\title{
The Action of $p$-Synephrine on Lipid Metabolism in the Perfused Rat Liver
}

\section{Juliany Fontoura da Silva-Pereira1, Andrea Luiza de Oliveira Valoto², Lívia Bracht' ${ }^{1}$, Geferson de Almeida Gonçalves ${ }^{1}$, Rosane Marina Peralta ${ }^{1}$, Adelar Bracht ${ }^{1}$}

\author{
${ }^{1}$ Department of Biochemistry, University of Maringá, Maringá, Brazil \\ ${ }^{2}$ Faculdade Integrado, Campo Mourão, Brazil \\ Email: adebracht@uol.com.br
}

How to cite this paper: da Silva-Pereira, J.F., de Oliveira Valoto, A.L., Bracht, L., de Almeida Gonçalves, G., Peralta, R.M. and Bracht, A. (2017) The Action of p-Synephrine on Lipid Metabolism in the Perfused Rat Liver. Journal of Biosciences and Medicines, 5, 8-21.

https://doi.org/10.4236/jbm.2017.55002

Received: April 25, 2017

Accepted: May 23, 2017

Published: May 26, 2017

Copyright $\odot 2017$ by authors and Scientific Research Publishing Inc. This work is licensed under the Creative Commons Attribution International License (CC BY 4.0).

http://creativecommons.org/licenses/by/4.0/

(c) (i) Open Access

\begin{abstract}
$p$-synephrine and p-octopamine were found to increase lipolysis in adipocytes. The present study approaches the question if these compounds, natural products of the bitter orange (Citrus aurantium fruit), increase lipolysis and fatty acid oxidation in the liver. Experiments were done in the perfused rat liver. Non-recirculating hemoglobin-free perfusion was done using the Krebs/ Henseleit-bicarbonate buffer ( $\mathrm{pH}$ 7.4) as perfusion fluid. Both $p$-synephrine and $p$-octopamine, at the concentrations of $100 \mu \mathrm{M}$, were found to stimulate the hepatic triacylglycerol lipase by $40 \%$ and $51 \%$, respectively. These seem to be the maximal stimulations possible in the liver. In the perfused liver, $p$-synephrine, when present at an initial concentration of $500 \mu \mathrm{M}$, was able to increase the non-esterified fatty acid release after one hour of recirculating perfusion. The effects of $p$-synephrine on the oxidation of exogenously supplied $\left[1-{ }^{14} \mathrm{C}\right]$ octanoate and $\left[1-{ }^{14} \mathrm{C}\right]$ oleate were minimal. Only oxygen uptake, already stimulated by octanoate or oleate, was additionally increased by the infusion of $p$-synephrine. These results contrast with those obtained in a previous study with $p$-octopamine, which increased the production of ${ }^{14} \mathrm{CO}_{2}$ from both $\left[1-{ }^{14} \mathrm{C}\right]$ octanoate and $\left[1-{ }^{14} \mathrm{C}\right]$ oleate. Apparently only the oxidation of endogenous fatty acids is stimulated by $p$-synephrine. On the other hand, both $p$-synephrine and $p$-octopamine stimulate the hepatic triacylglycerol lipase to a much lesser extent than the adipocyte lipase. It can be concluded that $p$-synephrine affects much more carbohydrate metabolism in the liver than lipid metabolism.
\end{abstract}

\section{Keywords}

Hepatic Lipid Metabolism, Lipolysis, Fatty Acid Release, Fatty Acid Oxidation 


\section{Introduction}

The fruit of Citrus aurantium, also known as bitter orange, has been used for preparing extracts sold worldwide in the form of phytoproducts to promote weight loss [1] [2] [3]. One of the main active components in $C$. aurantium extracts is $p$-synephrine, which in humans is found only in the adrenal gland and can be considered a trace bioamine [2]. In line with the proposed weight loss activity of the $C$. aurantium extracts, it has been found that $p$-synephrine has lipolytic activity in both human and rat adipocytes [1]. This activity of $p$-synephrine is stronger in rat than in human adipocytes. Since $p$-synephrine is the main proto alkaloid in $C$. aurantium extracts, the possible lipid-mobilizing effect of this extract in humans has been attributed to this amine [1]. Several studies have reported the activity of this compound on specific receptors. It has been shown, for example, that $p$-synephrine binds to serotoninergic receptors [4]. Likewise, an action of $p$-synephrine via adrenergic receptors has been documented [5] [6] [7]. Acute oral administration of elevated doses of a C. aurantium extract or $p$ synephrine produced reversible toxic effects, probably due to unspecific adrenergic stimulation [3]. In addition, it is also known that extracts of $C$. aurantium containing $p$-synephrine, can produce effects on the cardiovascular system through adrenergic stimulation [8].

It has also been shown that $p$-synephrine affects carbohydrate metabolism in the isolated perfused rat liver [9] [10]. In the latter systemp-synephrine stimulates glycogenolysis, glycolysis, gluconeogenesis, and oxygen uptake. The compound also increases the portal perfusion pressure and the redox state of the cytosolic $\mathrm{NAD}^{+} / \mathrm{NADH}$ couple. All these effects are $\mathrm{Ca}^{2+}$-dependent and $p$-synephrine is able to stimulate intracellular $\mathrm{Ca}^{2+}$ movements [9]. Moreover, $p$-synephrine also increases cAMP production. These observations and the sensibility to various adrenergic antagonists lead to the conclusion that the effects of $p$ synephrine in the liver are mediated by both $\alpha$ - and $\beta$-adrenergic signaling, requiring the simultaneous participation of both $\mathrm{Ca}^{2+}$ and cAMP. The metabolic effects, on the other hand, can be considered as both catabolic (glycogenolysis and glycolysis stimulation) and anabolic (gluconeogenesis) [9]. They could be contributing to the alleged weight loss effects of the compound ingested either in pure form or as a constituent of commercial preparations [1] [2] [3].

Although the action of $p$-synephrine on hepatic carbohydrate metabolism has been extensively characterized [9] [10], a similar investigation of its effects on the hepatic lipid metabolism has not yet been done. The lipolytic activity of $p$-synephrine in adipocytes has been well characterized [1] [6] and it is possible that the compound exerts a similar effect in the liver. Furthermore, p-octopamine, an analogous amine that is also found in Citrus aurantium, though at a lesser concentration, has been demonstrated to exert lipolytic activity in adipocytes [1] [6]. In the perfused rat liver, the compound also increases fatty acid oxidation [11]. The present study, thus, approaches the question if $p$-synephrine also increases lipolysis and fatty acid oxidation in the liver. Experiments were done in the perfused rat liver, a system that allows conservation of cell and mi- 
crocirculation integrity, facilitating thus extrapolation of the data to the in vivo conditions. The results should improve the present knowledge about the action of $p$-synephrine in the liver and also allow to design in vivo experiments that can confirm or not if the compound exerts metabolic effects in the whole organism. Furthermore, the experiments will be especially useful in answering the question if $p$-synephrine is able to affect hepatic lipid metabolism to the same extent by which it affects carbohydrate metabolism [9] [10].

\section{Materials and Methods}

\subsection{Materials}

The liver perfusion apparatus was built in the workshops of the University of Maringá. p-synephrine, $p$-octopamine, epinephrine, norepinephrine, enzymes and coenzymes used in the enzymatic assays, the nonesterified fatty-acid assay kit and the lipase assay kit were purchased from Sigma-Aldrich (St. Louis, USA). The radiochemicals were purchased from Amersham Pharmacia Biotech: $\left[1-{ }^{14} \mathrm{C}\right]$ oleic acid $(56 \mathrm{mCi} / \mathrm{mmol})$ and $\left[1-{ }^{14} \mathrm{C}\right]$ octanoic acid $(50 \mathrm{mCi} / \mathrm{mmol})$.

\subsection{Animals}

Male Wistar rats weighing 200 - $280 \mathrm{~g}$ were used in all experiments and fed ad libitum with a standard laboratory diet (Nuvilab ${ }^{\oplus}$, Colombo, Brazil). The rats were housed in appropriate cages and maintained on a regulated light-dark cycle. According to each experimental protocol fed rats as well as $18 \mathrm{~h}$ fasted rats were used. The surgical preparation of the liver was done under sodium pentobarbital anesthesia $(50 \mathrm{mg} / \mathrm{Kg})$. The criterion of anesthesia was the lack of body or limb movement when a standard tail clamping stimulus was applied [12] [13]. The world-wide accepted ethical guidelines for animal experimentation were applied strictly to all experiments. The experimental protocol was approved by the Ethics Committee of Animal Experimentation of the University of Maringá (Protocol n. 108/2014).

\subsection{Liver Perfusion}

The livers were perfused with a hemoglobin-free medium [12] [13]. In most experiments the nonrecirculating mode was used, but the release of nonesterified fatty acids was measured using recirculating perfusion. After the surgical preparation (vena cava and vena porta cannulation) the organ was transferred to a plexiglass chamber. The fluid was pumped using a peristaltic pump (Minipuls 3, Gilson, France) and the flow rate was adjusted between 30 and $33 \mathrm{~mL}$ per minute, according to the liver weight. The perfusion fluid was Krebs/Henseleitbicarbonate buffer ( $\mathrm{pH}$ 7.4) containing $25 \mathrm{mg} \%$ bovine-serum albumin [12] [13]. It was saturated with a mixture of oxygen and carbon dioxide (95:5) by means of a membrane oxygenator with simultaneous temperature adjustment $\left(37^{\circ} \mathrm{C}\right)$. The composition of the Krebs/Henseleit-bicarbonate buffer is the following [12] [13]: $115 \mathrm{mM} \mathrm{NaCl}, 25 \mathrm{mM} \mathrm{NaHCO}_{3}, 5.8 \mathrm{mM} \mathrm{KCl}, 1.2 \mathrm{mM} \mathrm{Na}_{2} \mathrm{SO}_{4}$, $1.18 \mathrm{mM} \mathrm{MgCl}_{2}, 1.2 \mathrm{mM} \mathrm{NaH}_{2} \mathrm{PO}_{4}$ and $2.5 \mathrm{mM} \mathrm{CaCl}_{2}$. The effluent perfusion 
fluid was fractionated generally in two minute intervals. After collection, the perfusate samples were analyzed for their metabolite contents. $p$-synephrine and all other agents were added to the perfusion fluid at the desired concentrations.

\subsection{Metabolite and Radioactivity Assay}

Three compounds were assayed in the effluent perfusion fluid using standard enzymatic procedures: $\beta$-hydroxybutyrate, acetoacetate and nonesterified fatty acids [14]. Acetoacetate was assayed by measuring the decrease in absorbance at $340 \mathrm{~nm}$ due to $\mathrm{NADH}$ oxidation $\left(\varepsilon=6.22 \times 10^{3} \mathrm{M}^{1} \cdot \mathrm{cm}^{1}\right)$ in a medium containing 0.03 units $/ \mathrm{mL} \beta$-hydroxybutyrate dehydrogenase, $0.2 \mathrm{mM} \mathrm{NADH}$ and $0.15 \mathrm{mM}$ triethanolamine ( $\mathrm{pH}$ 7.0). The assay of $\beta$-hydroxybutyrate was done by measuring the increase in absorbance due to the formation of NADH in a medium containing 0.03 units $/ \mathrm{mL} \beta$-hydroxybutyrate dehydrogenase, $1 \mathrm{mM} \mathrm{NAD}{ }^{+}, 0.15$ $\mathrm{mM}$ hydrazine and $0.15 \mathrm{mM}$ glycine ( $\mathrm{pH} 8.5$ ). The nonesterified fatty acid concentration was determined using the FFA Quantification Kit from Sigma-Aldrich (CN MAK044). In this kit, the concentration of fatty acids (C8 and longer) is determined by a coupled enzyme assay, which results in a product absorbing at $570 \mathrm{~nm}$ [15] [16]. Quantification was done by means of a calibration curve constructed with palmitic acid. The rates of metabolite release were calculated from the outflowing concentration and the total flow rate and expressed as $\mu \mathrm{mol}$ per minute per liver wet weight $\left(\mu \mathrm{mol} \min ^{1} \cdot \mathrm{g}^{1}\right)$. The oxygen concentration in the outflowing perfusate was recorded polarograhically. The sensor was a Teflonshielded platinum electrode, appropriately positioned in a plexiglass chamber at the exit of the perfusate [13].

For measuring the ${ }^{14} \mathrm{CO}_{2}$ production from the infused $\left[1-{ }^{14} \mathrm{C}\right]$ octanoate or $\left[1-{ }^{14} \mathrm{C}\right]$ oleate, Erlenmeyer flasks were used to collected the outflowing perfusate in 2-minute intervals [11]. Scintillation vials containing phenylethylamine were fastened by means of stainless steel wires to the rubber stoppers used to close the Erlenmeyer flasks. The ${ }^{14} \mathrm{CO}_{2}$ in the perfusion fluid was transferred to phenylethylamine by acidification of the perfusate with an $\mathrm{HCl}$ solution which was injected into the flasks through the rubber stoppers. Liquid scintillation spectroscopy was used for counting radioactivity. The following scintillation solution was used: toluene/ethanol (2/1) containing $5 \mathrm{~g} / \mathrm{L}$ 2,5-diphenyloxazole and 0.15 g/L 2,2-p-phenylene-bis(5-phenyloxazole) [11]. The rate of ${ }^{14} \mathrm{CO}_{2}$ production was calculated from the rate of radioactivity infusion and the specific activity of each labeled fatty acid.

\subsection{Hepatic Lipase Assay}

The hepatic lipase was assayed in the isolated perfused liver under various conditions (e.g., after 20 minutes $p$-synephrine infusion). After interruption of the perfusion at the desired time approximately $5 \mathrm{~g}$ of the hepatic tissue was collected and added to $20 \mathrm{~mL}$ of Tris- $\mathrm{HCl}$ buffer ( $\mathrm{pH} 8.0$ ) supplemented with fatty acid-free bovine-serum albumin to a final concentration of $2 \%$ [17]. After mincing with scissors, the tissue was homogenized in a van Potter homogenizer. The 
homogenate was filtered through gauze and the filtrate was centrifuged at $10,000 \mathrm{~g}$ for 10 minutes. After removing the fatty upper layer the supernatant was collected and used for the lipase assay. For the assay a commercial kit was used, which consists in coupled enzymatic reactions in which the released glycerol is quantified at $570 \mathrm{~nm}$. The activity was expressed as $\mu \mathrm{mol}$ glycerol released per minute per g liver wet weight.

\subsection{Statistical Analyses and Calculations}

The error parameters presented in the graphs are standard errors of the means. Statistical analysis was performed with the GraphPad Prism Software ${ }^{\bullet}$ (version 5.0; Graph Pad Software, San Diego, USA). The paired Student's t test was applied when comparing different metabolic steady-states and the $5 \%$ level $(\mathrm{p}<$ 0.05 ) was adopted as a criterion of significance. Anova followed by StudentNewman-Keuls testing was used for comparing multiple variables and the 5\% level $(\mathrm{p}<0.05)$ was adopted as a criterion of significance.

\section{Results and Discussion}

\subsection{Effect of $p$-Synephrine on the Hepatic Triacylglycerol Lipase}

In the first experiments the actions of $p$-synephrine and other structural analogues on the hepatic triacylglycerol lipase activity were investigated. The measurements were done after 20 minutes of infusion of each adrenergic agent at the concentrations specified on the graph in Figure 1. The infusion time of $20 \mathrm{mi}-$ nutes was established because at this time stimulation of oxygen uptake caused by the adrenergic agents in the perfused liver had already stabilized [9] [11] [18] [19]. The mean triacylglycerol lipase activity in the perfused liver without the infusion of any adrenergic effector was equal to $0.207 \pm 0.007 \mu \mathrm{mol}$ glycerol released per minute per $\mathrm{g}$ liver, what corresponds to $0.621 \pm 0.013 \mu \mathrm{mol}$ fatty acid released $\min ^{-1} \cdot g \cdot l i v e r^{-1}$. A similar activity has been reported previously for livers homogenized just after removing them from decapitated rats without perfusion [20]. Figure 1 shows that all adrenergic agents tested in the present experiments tended to increase the hepatic triacylglycerol lipase. Stimulation caused by 100 $\mu \mathrm{M}$ p-synephrine was $40 \%$ and that caused by $100 \mu \mathrm{M}$ p-octopamine $51 \%$. These stimulations were similar to that caused by $10 \mu \mathrm{M}$ norepinephrine. The stimulating actions of 50 and $100 \mu \mathrm{M} p$-synephrine were nearly the same. This means that more than $40 \%-50 \%$ stimulation of the hepatic triacylglycerol lipase activity is unlikely to be achieved by increasing the concentration of $p$-synephrine. The capacity of $p$-synephrine in stimulating the hepatic triacylglycerol lipase activity seems to be much less pronounced than that reported for the adipose tissue. In rat adipocytes stimulation of the triacylglycerol lipase by $100 \mu \mathrm{M} p$-synephrine is already maximal and corresponds to a 4.8 fold stimulation (i.e., $380 \%$ ) [1].

\subsection{Nonesterified Fatty Acid Release}

The action of $p$-synephrine on nonesterified fatty acid release in the liver was 


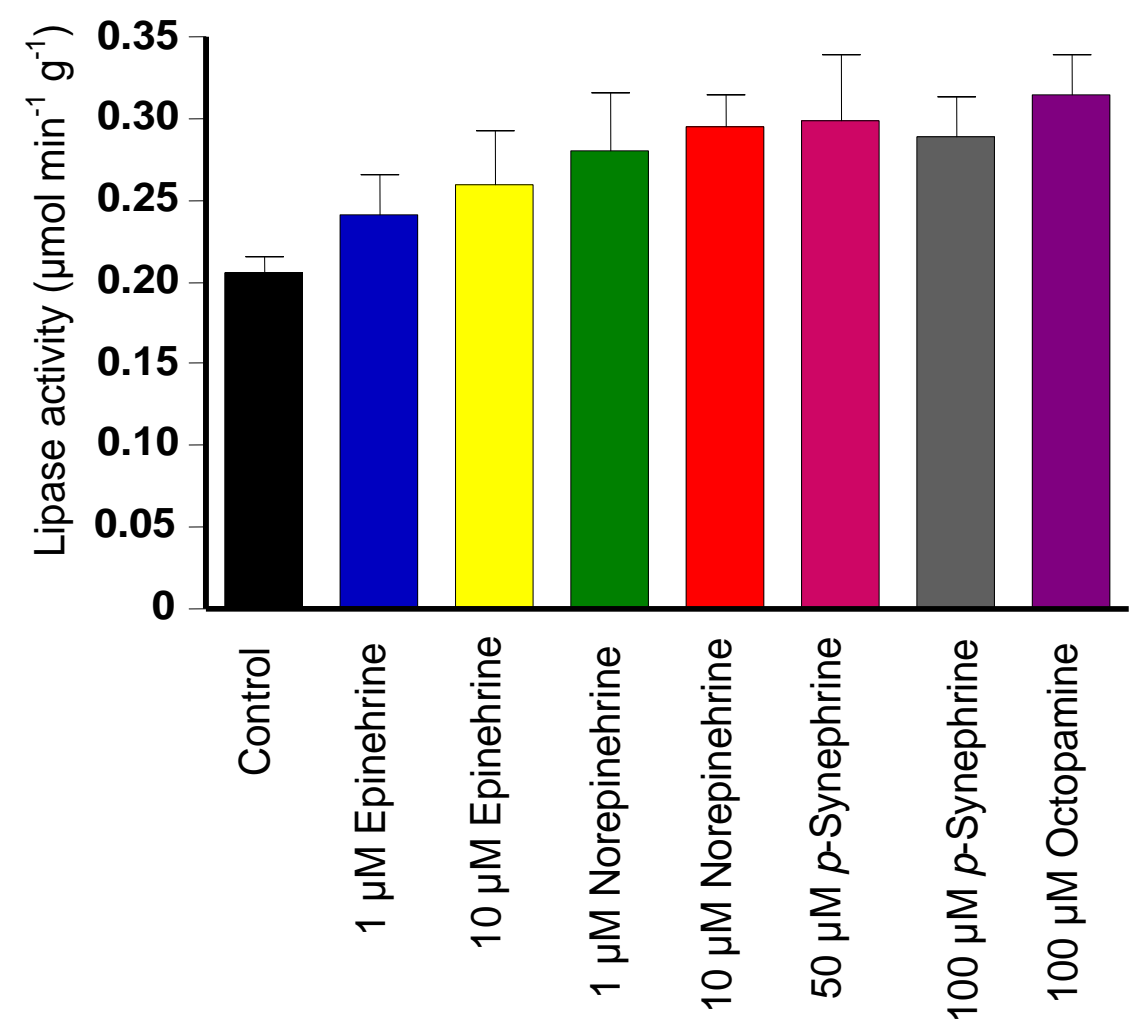

Figure 1. Effects of several adrenergic agents on the hepatic triacylglycerol lipase activity. Rat livers were perfused in the non-recirculating mode with Krebs/Henseleit-bicarbonate buffer ( $\mathrm{pH}$ 7.4) saturated with a mixture of oxygen and carbon dioxide $\left(\mathrm{O}_{2}: \mathrm{CO}_{2}: 95: 5 \%\right)$ as described in the Materials and Methods section. The tissue was prepared for the lipase assay as described in the Materials and Methods section after 20 minutes infusion of each adrenergic agent at the concentrations specified on the graph. Each experimental curve is the mean \pm mean standard errors of five liver perfusion experiments. Statistically significant differences compared to the control condition (i.e., $\mathrm{p} \leq 0.05$ ) were found only for $10 \mu \mathrm{M}$ norepinephrine, $100 \mu \mathrm{M} p$-synephrine and $100 \mu \mathrm{M}$ p-octopamine.

investigated using recirculating perfusion. Stimulation of fatty acid release by $p$-synephrine can be expected due to its stimulatory effect on the triacylglycerol lipase. Figure 2 shows the mean results of the experiments that were done in the present work. Two initial $p$-synephrine concentrations were used, 50 and 500 $\mu \mathrm{M}$. As reported elsewhere, the single passage extraction (transformation) of $p$-synephrine is relatively high and inversely proportional to the concentration [21]. Consequently, in a recirculating system the concentration of $p$-synephrine in the perfusion fluid decreases rapidly, especially at low concentrations. Figure 2 shows that the concentration of fatty acids tended to increase as the recirculation progressed. This increase was not very pronounced, as the release of nonesterified fatty acids into the plasma is an important function of the peripheral fattissue but not of the liver [22]. The presence of $50 \mu \mathrm{M} p$-synephrine did not increase the extracellular fatty acid accumulation. With $500 \mu \mathrm{M} p$-synephrine, however, there was an increment in fatty acid accumulation, statistically significant after 60 minutes of recirculation. This observation is consistent with a sti- 
mulation of the triacylglycerol lipase by $p$-synephrine. However, it does not correspond to the degree of stimulation of the lipolytic activity because it is highly probable that most fatty acids released intracellularly are oxidized in the respiratory chain.

\subsection{Effects of $p$-Synephrine on Fatty Acid Oxidation}

The effects of $200 \mu \mathrm{M}$ octopamine on fatty acid oxidation were examined in a previous work. For comparative purposes, thus, similar experiments were done with $200 \mu \mathrm{M} p$-synephrine. In these experiments $\left[1-{ }^{14} \mathrm{C}\right]$ octanoate (a mediumchain fatty acid) and $\left[1-{ }^{14} \mathrm{C}\right]$ oleate (long-chain fatty acid) were infused in livers from fasted rats, allowing to measure the productions of ${ }^{14} \mathrm{CO}_{2}$ and ketone bodies ( $\beta$-hydroxybutyrate and acetoacetate) in addition to the rate of oxygen uptake. The time courses of the experiments are shown in Figure 3 (octanoate) and Figure 4 (oleate) and the changes caused by p-synephrine in oxygen uptake

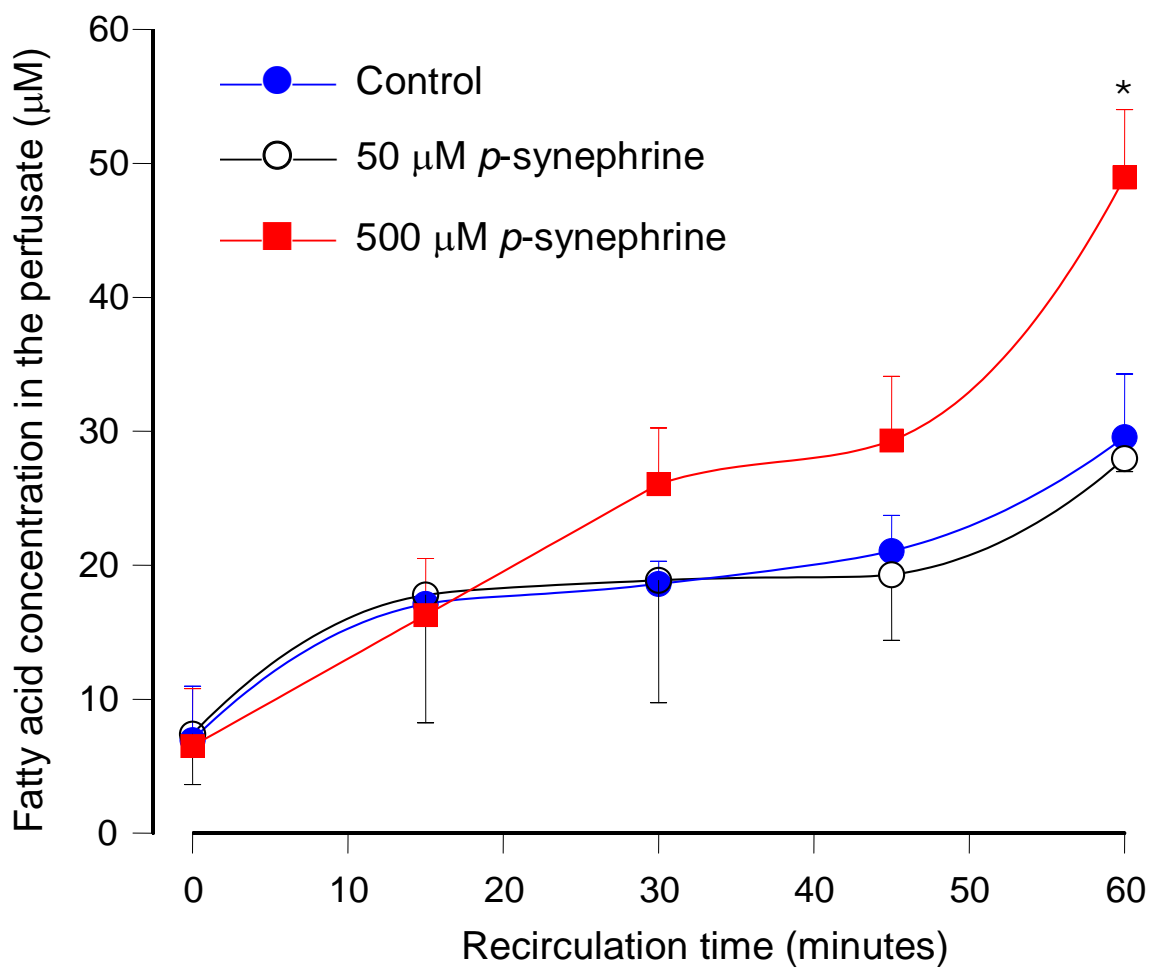

Figure 2. The action of $p$-synephrine on nonesterified fatty acid release in the rat liver perfused in the recirculating mode. Rat livers were initially perfused in the non-recirculating mode with Krebs/Henseleit-bicarbonate buffer ( $\mathrm{pH} 7.4$ ) saturated with a mixture of oxygen and carbon dioxide $\left(\mathrm{O}_{2}: \mathrm{CO}_{2}: 95: 5 \%\right)$ and containing $1 \mathrm{~g} \%$ fatty acid free bovine serum albumin. After the addition of p-synephrine at the desired final concentration (50 or $500 \mu \mathrm{M})$ to the perfusion fluid the outflowing perfusate was allowed to accumulate until reaching a total circulating volume of $190 \mathrm{~mL}$. At this moment recirculating perfusion was started. Samples were collected at various times for the enzymatic assay of non-esterified fatty acids. Each experimental curve is the mean \pm mean standard errors of three liver perfusion experiments. The asterisk indicates the only statistical difference between the control and the $500 \mu \mathrm{M}$ p-synephrine condition as given by the StudentNewman-Keuls test $(\mathrm{p} \leq 0.05)$. 
are listed in Table 1. The concentrations of the fatty acids are compatible with the physiological range at which these metabolites are present in the circulation [23].

Figure 3 shows that the introduction of $\left[1-{ }^{14} \mathrm{C}\right]$ octanoate into the perfusion fluid causes immediate increases in oxygen consumption and $\beta$-hydroxybutyrate production, with no change in acetoacetate production.

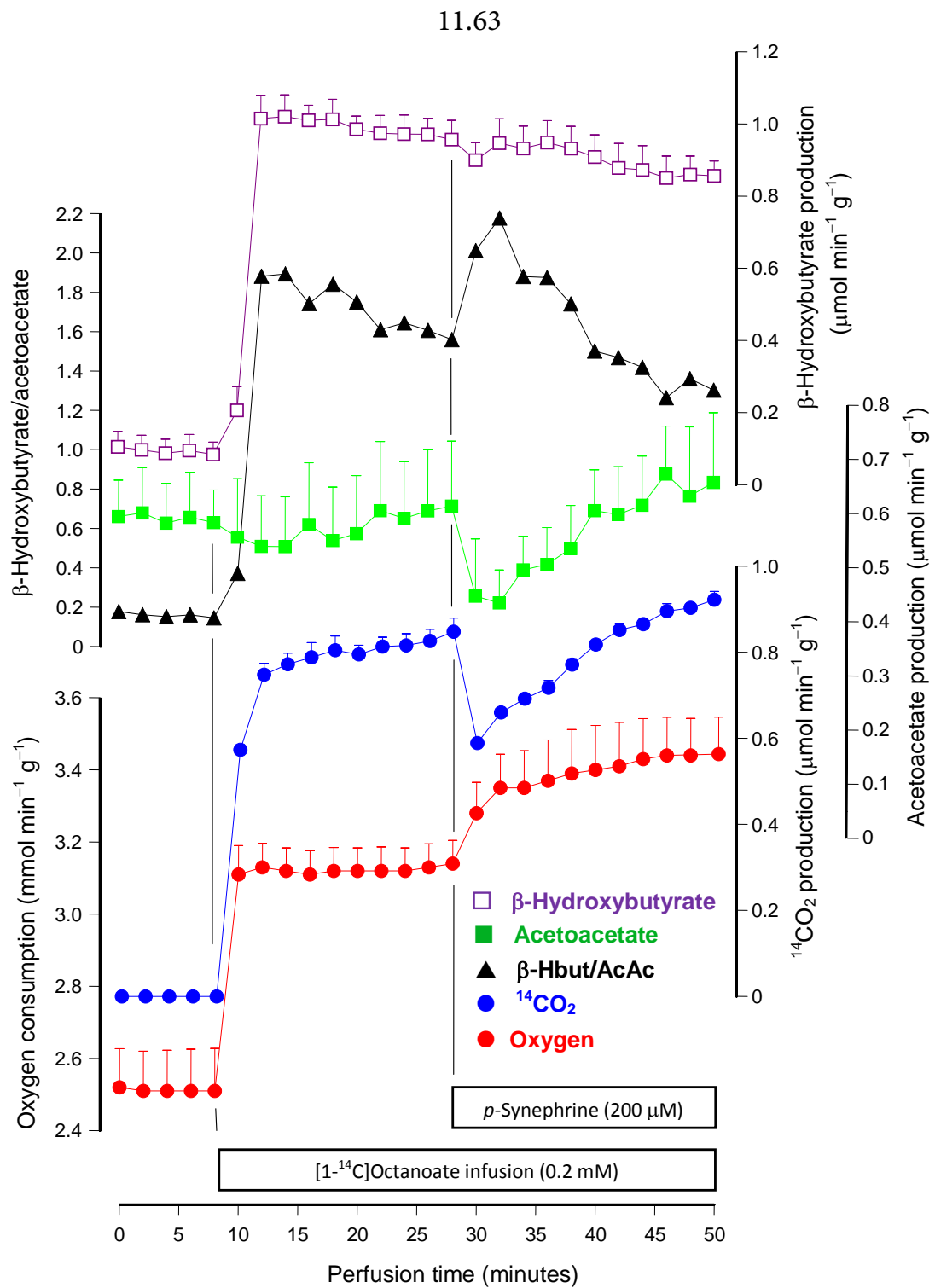

Figure 3. Time courses of the changes caused by $\mu \mathrm{M} 200$ p-synephrine on the metabolic fluxes caused by octanoate in the perfused rat liver. Livers of fasted rats were perfused as described in the experimental section. The infusions of $\left[1-{ }^{14} \mathrm{C}\right]$ octanoate $(0.2 \mathrm{mM})$ and $\mathrm{p}$-synephrine are indicated in the boxes near to the time scale. Samples of the outflowing perfusate were collected for the enzymatic assay of acetoacetate and $\beta$-hydroxybutyrate. The oxygen concentration in the outflowing perfusate was measured polarographically. Radioactivity was measured after trapping the ${ }^{14} \mathrm{CO}_{2}$ in the perfusate samples as $\left[{ }^{14} \mathrm{C}\right]$ bicarbonate in phenylethylamine. Datum points are means \pm mean standard errors of 3 4 liver perfusion experiments. 


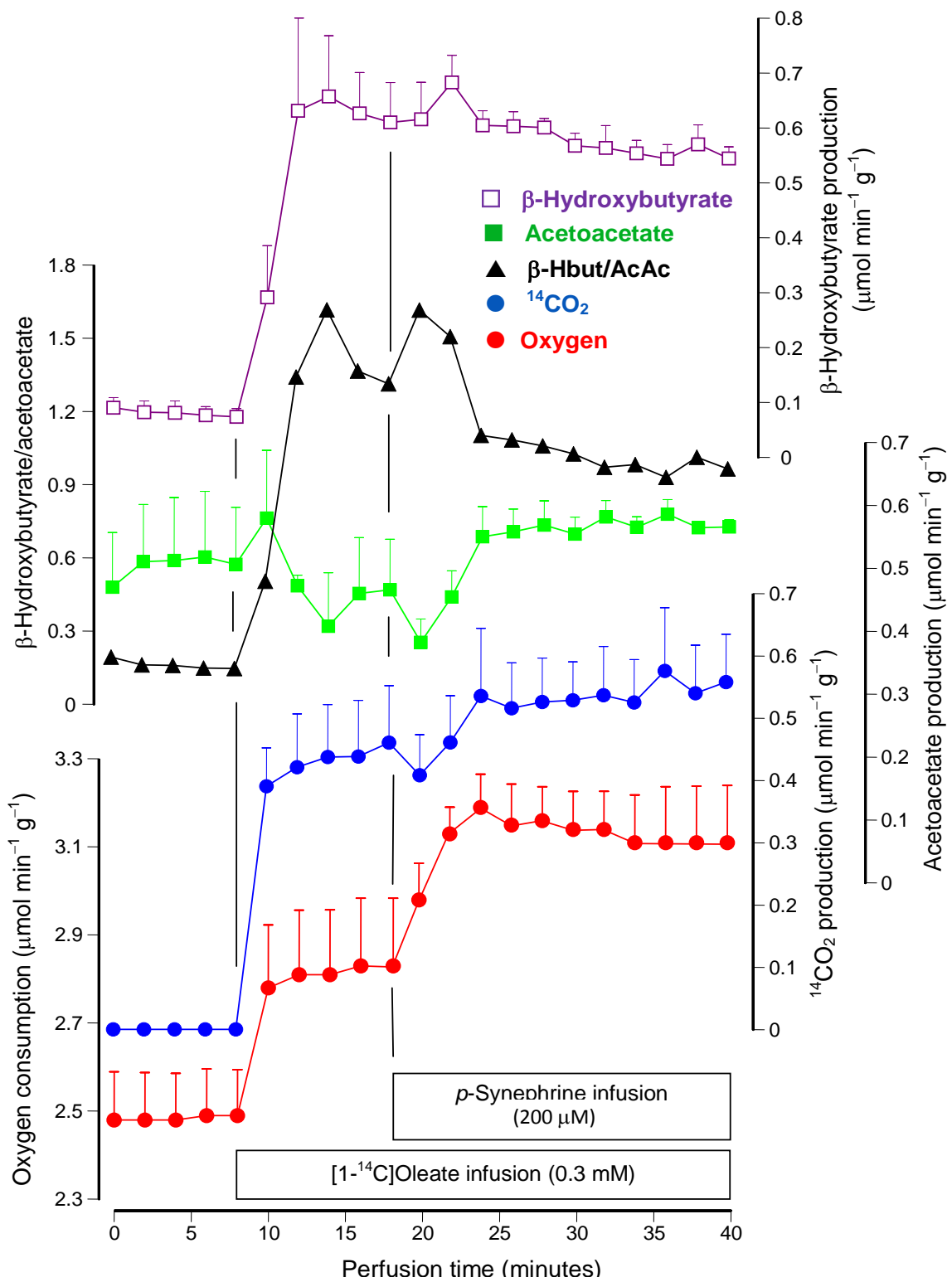

Figure 4. Time courses of the changes caused by $200 \mu \mathrm{M}$ p-synephrine on the metabolic fluxes caused by oleate in the perfused rat liver. Livers of fasted rats were perfused as described in the experimental section. The infusions of $\left[1-{ }^{14} \mathrm{C}\right]$ oleate $(0.3 \mathrm{mM}$ with 0.15 $\mathrm{mM}$ fatty acid free bovine serum albumin) and $p$-synephrine are indicated in the boxes near to the time scale. Samples of the outflowing perfusate were collected for the enzymatic assay of acetoacetate and $\beta$-hydroxybutyrate. The oxygen concentration in the outflowing perfusate uptake was measured polarographically. Radioactivity was measured after trapping the ${ }^{14} \mathrm{CO}_{2}$ in the perfusate samples as $\left[{ }^{14} \mathrm{C}\right]$ bicarbonate in phenylethylamine. Datum points are means \pm mean standard errors of 3 - 4 liver perfusion experiments.

This means also a substantial increase in the $\beta$-hydroxybutyrate/acetoacetate ratio, evidence of an increased availability of reducing equivalents in the respiratory chain [24]. The ${ }^{14} \mathrm{CO}_{2}$ production raised rapidly following the $\left[1-{ }^{14} \mathrm{C}\right]$ octanoate introduction, evidence of an intense oxidation of this fatty acid. $p$-synephrine was introduced at 28 minutes perfusion time when all the meta- 
Table 1. Stimulation of oxygen uptake by $200 \mu \mathrm{M}$ p-synephrine under several conditions. The increments in oxygen uptake represent differences between steady-states. The error parameters are standard errors of the mean; asterisks indicate the statistical significance of each increment given by the Student's paired t test $(\mathrm{p} \leq 0.05)$.

\begin{tabular}{cccc}
\hline Substrate & $\begin{array}{c}\text { Animal } \\
\text { condition }\end{array}$ & $\begin{array}{c}\text { Increment caused by } \\
\text { substrate infusion } \\
\left(\mu \mathrm{mol} \mathrm{O} \mathrm{min}^{1} \cdot \mathrm{g}^{1}\right)\end{array}$ & $\begin{array}{c}\text { Increment caused by } \\
\text { p-synephrine infusion } \\
\left(\mu \mathrm{mol} \mathrm{O} \mathrm{min}^{1} \cdot \mathrm{g}^{1}\right)\end{array}$ \\
\hline Substrate-free $(\mathrm{n}=4)^{\mathrm{a}}$ & Fed & - & $0.466 \pm 0.099^{*}$ \\
Lactate $(2 \mathrm{mM})(\mathrm{n}=3)^{\mathrm{a}}$ & Fasted & $0.702 \pm 0.029^{*}$ & $0.296 \pm 0.102^{*}$ \\
Octanoate $(0.2 \mathrm{mM})(\mathrm{n}=3)^{\mathrm{b}}$ & Fasted & $0.667 \pm 0.050^{*}$ & $0.307 \pm 0.057^{*}$ \\
Oleate $(0.3 \mathrm{mM})(\mathrm{n}=3)^{\mathrm{b}}$ & Fasted & $0.410 \pm 0.106^{*}$ & $0.340 \pm 0.017^{*}$ \\
\hline
\end{tabular}

${ }^{\mathrm{a}}$ Data obtained from [9], ${ }^{\mathrm{b}}$ This work (data obtained from Figure 3 and Figure 4).

bolic variables modified by octanoate had already stabilized (steady-states). The introduction of $p$-synephrine caused transient diminutions in the productions of acetoacetate and ${ }^{14} \mathrm{CO}_{2}$. The peak diminutions were equal to $-0.179 \pm 0.059(\mathrm{p}=$ $0.095)$ and $-0.259 \pm 0.034(\mathrm{p}=0.017) \mu \mathrm{mol} \mathrm{min}^{-1} \cdot \mathrm{g}^{-1}$, respectively. After these peak diminutions there was a progressive recovery to the previous levels that was almost completed at the end of the experiment (20 minutes of $p$-synephrine infusion). Oxygen uptake, however, was additionally increased to a new steady state. This significant increment, given in Table 1, is similar to that observed when $p$-synephrine was infused in the presence of $2 \mathrm{mM}$ lactate, but smaller than that found when the compound was infused in livers under substrate-free perfusion [9].

Figure 4 shows the time courses of the experiments that were done with $\left[1-{ }^{14} \mathrm{C}\right]$ oleate. The modifications caused by the infusion of $\left[1-{ }^{14} \mathrm{C}\right]$ oleate were similar to that caused by the infusion of $\left[1-{ }^{14} \mathrm{C}\right]$ octanoate except for a small diminution in the production of acetoacetate caused by oleate, which did not occur upon octanoate infusion. The introduction of $p$-synephrine in the presence of $\left[1-{ }^{14} \mathrm{C}\right]$ oleate did not produce the transient diminutions in the production of acetoacetate and ${ }^{14} \mathrm{CO}_{2}$ that were observed when $\left[1-{ }^{14} \mathrm{C}\right]$ octanoate was introduced (compare Figure 3 and Figure 4). On the other hand, besides the clear additional increase in oxygen uptake, similar to that found in the presence of octanoate (see Table 1), the infusion of $p$-synephrine in the presence of $\left[1-{ }^{14} \mathrm{C}\right]$ oleate also caused a small increasein the acetoacetate production $(+0.183$ $\left.\pm 0.03 \mu \mathrm{mol} \min ^{-1} \cdot \mathrm{g}^{-1} ; \mathrm{p}=0.027\right)$. This increase in the acetoacetate production without a corresponding modification in the $\beta$-hydroxybutyrate production also means that the $\beta$-hydroxybutyrate/acetoacetate ratio was slightly diminished by $p$-synephrine, as indeed shown by Figure 4 . There was also a tendency toward higher rates of ${ }^{14} \mathrm{CO}_{2}$ production upon $p$-synephrine infusion, but statistical significance was lacking at the $5 \%$ level.

The action of $200 \mu \mathrm{M} p$-synephrine on the oxidation of exogenous fatty acids differs from the action of $200 \mu \mathrm{M} p$-octopamine in that the former was unable to increase significantly the ${ }^{14} \mathrm{CO}_{2}$ production from either $\left[1-{ }^{14} \mathrm{C}\right]$ octanoate or $\left[1-{ }^{14} \mathrm{C}\right]$ oleate. The increases in ${ }^{14} \mathrm{CO}_{2}$ production caused by $200 \mu \mathrm{M} p$-octopamine following $\left[1-{ }^{14} \mathrm{C}\right]$ octanoate and $\left[1-{ }^{14} \mathrm{C}\right]$ oleate infusion are significant and 
equal to $0.36 \pm 0.09$ and $0.14 \pm 0.04 \mu \mathrm{mol} \mathrm{min}^{-1} \cdot \mathrm{g}^{-1}$ [11]. Additionally, $p$-octopamine also has a more pronounced effect on ketone bodies production than $p$-synephrine. In other words, $p$-octopamine clearly stimulates the oxidation of exogenous fatty acids whereas $p$-synephrine seems to act modestly in this respect. Under some circumstances the action of $p$-synephrine was even inhibitory, as evidenced by the transient inhibitory episodes of ${ }^{14} \mathrm{CO}_{2}$ and acetoacetate productions from $\left[1-{ }^{14} \mathrm{C}\right]$ octanoate already described above (Figure 3 ).

It is highly probable, however, that $p$-synephrine increases the oxidation of endogenous fatty acids. The arguments supporting this conclusion are as follows: 1) p-synephrine stimulates the hepatic triacylglycerol lipase (Figure 1), thus increasing the endogenous availability of nonesterified fatty acids to the point that a certain amount can even be released by the liver (Figure 2);2) $p$ synephrine increases oxygen uptake also in the absence of any exogenous substrate (Table 1; [9]), a condition where endogenous fatty acids are by far the main source of reducing equivalents to the respiratory chain [12] [25]; 3) $p$-synephrine increases oxygen uptake even when the liver is oxidizing exogenous $\left[1-{ }^{14} \mathrm{C}\right]$ fatty acids, without a corresponding increase in the ${ }^{14} \mathrm{CO}_{2}$ production; 4) $p$-synephrine also increases oxygen uptake under gluconeogenic conditions (Table 1), a situation in which the oxidation of endogenous fatty acids has been demonstrated to provide a considerable part of the reducing equivalents to the mitochondrial respiratory chain, especially when glucose synthesis is stimulated, as it in fact occurs in the presence of $p$-synephrine [9] [25] [26].

p-octopamine also stimulates the hepatic triacylglycerol lipase and, thus, also increases the availability of endogenous non-esterified fatty acids. Even so, this agent is able to increase the oxidation of exogenous fatty acids [11]. The mechanisms underlying these different behaviors of $p$-synephrine and $p$-octopamine cannot be inferred from the available data. $p$-octopamine and $p$-synephrine apparently bind to both alfa- and beta-adrenergic receptors in the liver and probably act via both cAMP and $\mathrm{Ca}^{2+}$ as intracellular messengers [9] [11]. It is possible that the different actions of $p$-octopamine and $p$-synephrine on fatty acid oxidation bear some relation to the different binding intensities to the various receptors. This is certainly a question that demands additional investigation.

\section{Conclusion}

The main conclusion which can be drawn from a comparison of the results obtained in the present study with those of previous investigations in the perfused liver [9] [10] is that $p$-synephrine acts more strongly on carbohydrate metabolism than on lipid metabolism in the liver. Even so, the lipolytic action of $p$-synephrine is an important component of some of its anabolic effects in the liver such as the stimulation of glucose synthesis, which depends, partly at least, on the oxidation of endogenous fatty acids as a means of supplying ATP and reducing equivalents [25] [26]. On the other hand, if p-synephrine is expected to mobilize fatty acids from other tissues (e.g., adipose tissue), no coordinated stimulation of their oxidation can be expected in the liver except that one given by 
its increased availability. Modest increases in the levels of circulating nonesterified fatty acids by $p$-synephrine have indeed been suggested to occur in humans based on the finding that administration of the drug resulted in higher glycerol levels [27]. It should be noted, however, that with reference to the ingestion of $C$. aurantium extracts, an extra stimulation of the oxidation of exogenous fatty acids in the liver could be expected, in theory at least, by virtue of their contents in p-octopamine [11].

\section{Acknowledgements}

This work was supported by grants from the Conselho Nacional de Desenvolvimento Científico e Tecnológico (CNPq). Juliany Fontoura da Silva-Pereira and Geferson de Almeida Gonçalves were fellowship holders of the Coordenação de Aperfeiçoamento de Pessoal do Ensino Superior (CAPES).

\section{References}

[1] Mercarder, J., Wanecq, E., Chen, J. and Carpéné, C. (2011) Isopropylnorsynephrine Is a Stronger Lipolytic Agent in Human Adipocytes than Synephrine and Other Amines Present in Citrus aurantium. Journal of Physiology and Biochemistry, 67, 443-452. https://doi.org/10.1007/s13105-011-0078-2

[2] Fugh-Berman, A. and Myers, A. (2004) Citrus aurantium, an Ingredient of Dietary Supplements Marketed for Weight Loss: Current Status of Clinical and Basic Research. Experimental Biology and Medicine, 29, 698-704.

[3] Arbo, M.D., Larentis, E.R., Linck, V.M., Aboy, A.L., Pimentel, A.L., Henriques, A.T., Dallegrave, E., Garcia, S.C., Leal, M.B. and Limberger, R.P. (2008) Concentrations of $p$-Synephrine in Fruits and Leaves of Citrus Species (Rutaceae) and the Acute Toxicity Testing of Citrus Aurantium Extract and $p$-Synephrine. Food and Chemical Toxicology, 46, 2770-2775. https://doi.org/10.1016/j.fct.2008.04.037

[4] Song, D.K., Suh, H.W., Jung, J.S., Wie, M.B., Son, K.H. and Kim, Y.H. (1996) Antidepressant-Like Effects of $p$-Synephrine in Mouse Models of Immobility Tests. Neuroscience Letters, 214, 107-110. https://doi.org/10.1016/0304-3940(96)12895-0

[5] Brown, C.M., McGrath, J.C., Midgley, J.M., Muir, A.G.B., O’Brien, J.W., Thonoor, C.M., Williams, C.M. and Wilson, V.G. (1988) Activities of Octopamine and Synephrine Stereoisomers on $\alpha$-Adrenoceptors. British Journal of Pharmacology, 93, 417-429. https://doi.org/10.1111/j.1476-5381.1988.tb11449.x

[6] Carpéné, C., Galitzky, J., Fontana, E., Atgié, C., Lafontan, M. and Berlan, M. (1999) Selective Activation of $\alpha_{3}$-Adrenoceptors by Octopamine: Comparative Studies in Mammalian Fat Cells. Naunyn-Schmiedeberg's Archives of Pharmacology, 359, 310-321. https://doi.org/10.1007/PL00005357

[7] Hibino, T., Yuzurihara, M., Kase, Y. and Takeda, A. (2009) Synephrine, a Component of Evodiae fructus, Constricts Isolated Rat Aorta via Adrenergic and Serotonergic Receptors. Journal of Pharmacological Sciences, 111, 73-81. https://doi.org/10.1254/jphs.09077FP

[8] Calapai, G., Firenzuoli, F., Saitta, A., Squadrito, F., Arlotta, M.R., Constantino, G. and Inferrera, G. (1999) Antiobesity and Cardiovascular Toxic Effects of Citrus Aurantium Extracts in the Rat: a Preliminary Report. Fitoterapia, 70, 586-592. https://doi.org/10.1016/S0367-326X(99)00093-3

[9] Oliveira, A.L., Comar, J.F., Sá-Nakanishi, A.B., Peralta, R.M. and Bracht, A. (2014) 
The Action of $p$-Synephrine on Hepatic Carbohydrate Metabolism and Respiration Occurs via both $\mathrm{Ca}^{2+}$-Mobilization and cAMP Production. Molecular and Cellular Biochemistry, 388, 135-147. https://doi.org/10.1007/s11010-013-1905-2

[10] Peixoto, J.S., Comar, J.F., Moreira, C.T., Soares, A.A., Oliveira, A.L., Bracht, A. and Peralta, R.M. (2012) Effects of Citrus aurantium (Bitter Orange) Fruit Extracts and p-Synephrine on Metabolic Fluxes in the Rat Liver. Molecules, 17, 5854-5869. https://doi.org/10.3390/molecules17055854

[11] Oliveira, A.L., Paula, M.N., Comar, J.F., Vilela, V.R., Peralta, R.M. and Bracht, A. (2013) Adrenergic, Metabolic and Hemodynamic Effects of Octopamine in the Liver. International Journal of Molecular Sciences, 14, 21858-21872. https://doi.org/10.3390/ijms141121858

[12] Scholz, R. and Bücher, T. (1965) Hemoglobin-free Perfusion of Rat Liver. In: Chance, B., Estabrook, R.W. and Williamson, J.R., Eds., Control of Energy Metabolism, Academic Press, New York, 393-414. https://doi.org/10.1016/B978-1-4832-3161-7.50048-3

[13] Bracht, A., Ishii-Iwamoto, E.L. and Kelmer-Bracht, A.M. (2003) O Estudo do Metabolismo no Fígado em Perfusão. In: Bracht, A. and Ishii-Iwamoto, E.L., Eds., Métodos de Laboratório em Bioquímica, Editora Manole, São Paulo, 275-289.

[14] Bergmeyer, H.U. (1974) Methods of Enzymatic Analysis. Verlag Chemie, Weinheim.

[15] Hauton, D. and Caldwell, G.M. (2012) Cardiac Lipoprotein Lipase Activity in the Hypertrophied Heart may be Regulated by Fatty Acid Flux. Biochimica et Biophysica Acta, 1821, 627-636. https://doi.org/10.1016/j.bbalip.2011.12.004

[16] Yamamoto, N.S., Ishii-Iwamoto, E.L. and Bracht, A. (1992) Activation of Glycogenolysis by Methotrexate: Effects of Calcium and Inhibitors of Hormone Action. Biochemical Pharmacology, 44, 761-767. https://doi.org/10.1016/0006-2952(92)90414-E

[17] Nascimento, E.A., Tonon, F.A., Bracht, A.M.K., Bracht, A. and Ishii-Iwamoto, E.L. (1997) Glycogenolysis Stimulation by Non-Steroidal Antiinflammatories in the Perfused Rat Liver Is Not Accompanied by Calcium Release. Research Communications in Molecular Pathology Pharmacology, 96, 193-201.

[18] Knauer, T.E., Woods, J.A., Lamb, R.G. and Fallon, H.J. (1982) Hepatic Triacylglycerol Lipase Activities after Induction of Diabetes and Administration of Insulin or Glucagon. Journal of Lipid Research, 23, 631-637.

[19] Silva-Pereira, J.F., Bubna, G.A., Gonçalves, G.A., Peralta, R.M. and Bracht, A. (2016) Fast Hepatic Biotransformation of $p$-Synephrine and Implications for Their Oral Intake. Food \& Function, 7, 1483-1491. https://doi.org/10.1039/C6FO00014B

[20] Wolfe, R.R. (1998) Metabolic Interactions between Glucose and Fatty Acids in Humans. Journal of Clinical Nutrition, 67, 519S-526S.

[21] Sies, H. (1982) Nicotinamide Nucleotide Compartmentation. In: Sies, H., Ed., Metabolic Compartmentation, Academic Press, London, 205-231.

[22] Parrilla, R., Ayuso-Parrilla, M.S. and Williamson, J.R. (1976) Use of Endogenous Triglycerides to Support Gluconeogenesis in the Perfused Isolated Rat Liver. Pflügers Archiv. European Journal of Physiology, 366, 211-216. https://doi.org/10.1007/BF00585880

[23] González-Manchón, C., Martín-Requero, A., Ayuso, M.S. and Parrilla, R. (1992) Role of Endogenous Fatty Acids in the Control of Hepatic Gluconeogenesis. Archives of Biochemistry and Biophysics, 292, 95-101. https://doi.org/10.1016/0003-9861(92)90055-2 
[24] Chilliard, Y., Bauchart, D. and Barnouin, J. (1984) Determination of Plasma NonEsterified Fatty Acids in Herbivores and Man: a Comparison of Values Obtained by Manual or Automatic Chromatographic, Titrimetric, Colorimetric and Enzymatic Methods. Reproduction Nutrition Development, 24, 469-482. https://doi.org/10.1051/rnd:19840412

[25] Mizuno, K., Toyosato, M., Yabumoto, S., Tanimizu, I. and Hirakawa, H. (1980) A New Enzymatic Method for Colorimetric Determination of Free Fatty Acids. Analytical Biochemistry, 108, 6-10. https://doi.org/10.1016/0003-2697(80)90686-7

[26] Mito, M.S., Constantin, J., Castro, C.V., Yamamoto, N.S. and Bracht, A. (2010) Effects of Ranolazine on Fatty Acid Transformation in the Isolated Perfused Rat Liver. Molecular and Cellular Biochemistry, 345, 35-44. https://doi.org/10.1007/s11010-010-0557-8

[27] Ratamess, N.A., Bush, J.A., Kang, J., Kraemer, W.J., Stohs, S.J., Nocera, V.G., Leise, M.D., Diamond, K.B., Campbell, S.C., Miller, H.B. and Faigenbaum, A.D. (2016) The Effects of Supplementation with $p$-Synephrine Alone and in Combination with Caffeine on Metabolic, Lipolytic and Cardiovascular Responses during Resistance Exercise. Journal of the American College of Nutrition, 35, 657-669. https://doi.org/10.1080/07315724.2016.1150223

\section{Submit or recommend next manuscript to SCIRP and we will provide best} service for you:

Accepting pre-submission inquiries through Email, Facebook, LinkedIn, Twitter, etc. A wide selection of journals (inclusive of 9 subjects, more than 200 journals)

Providing 24-hour high-quality service

User-friendly online submission system

Fair and swift peer-review system

Efficient typesetting and proofreading procedure

Display of the result of downloads and visits, as well as the number of cited articles Maximum dissemination of your research work

Submit your manuscript at: http://papersubmission.scirp.org/

Or contact jbm@scirp.org 